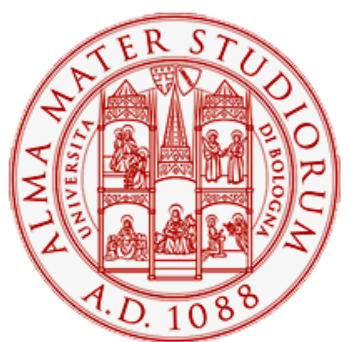

Alma Mater Studiorum - Università di Bologna DEPARTMENT OF ECONOMICS

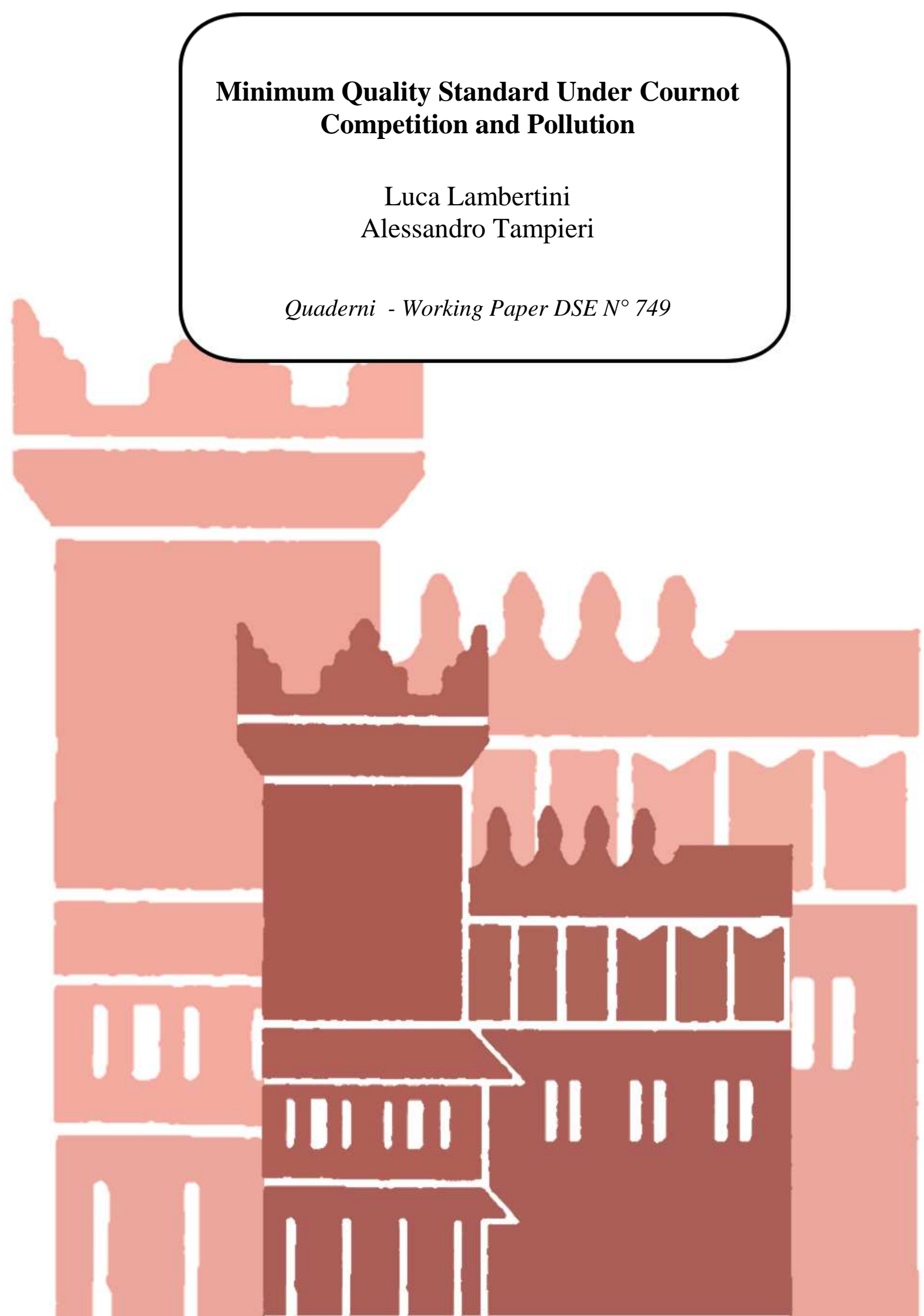




\title{
Minimum Quality Standard Under Cournot Competition and Pollution
}

\author{
Luca Lambertini ${ }^{\S, \#}$ and Alessandro Tampieri ${ }^{\S}$ \\ $\S$ Department of Economics, University of Bologna \\ Strada Maggiore 45, 40125 Bologna, Italy \\ luca.lambertini@unibo.it; alessandro.tampieri@unibo.it \\ \# ENCORE, University of Amsterdam \\ Roetersstraat 11, WB1018 Amsterdam, The Netherlands
}

May 10, 2011

\begin{abstract}
We extend the analysis carried out by Valletti (2000) by considering an environmental externality in a vertically differentiated duopoly where firms compete à la Cournot with fixed costs of quality improvement. We show that, if the weight of the external effect is high enough, the resulting minimum quality standard is indeed binding.
\end{abstract}

JEL codes: L13, L51, Q50.

Keywords: MQS, environmental externality, product quality. 


\section{Introduction}

In this note we extend the analysis carried out by Valletti (2000) by considering an environmental externality in a vertically differentiated duopoly where firms compete à la Cournot and incur in fixed costs of quality development. Valletti (2000) shows that quantity-setting behaviour implies a non-binding minimum quality standard (MQS), as Cournot competition is milder than Bertrand's. This conclusion, however, is based on a setting where undesirable environmental implications are not modelled and therefore any quality distortion is solely driven by the firms' profit incentives. Instead, our results show that the presence of a negative external effect increasing in industry output, if large enough, implies that the MQS will indeed bite at the regulated equilibrium, bringing about an increase in qualities and welfare and a decrease in the externality.

\section{The model}

We consider a duopoly market for vertically differentiated products supplied by single-product firms. The demand side is modelled à la Mussa and Rosen (1978). There is a continuum of consumers whose types are identified by $\theta$, uniformly distributed with density equal to one in the interval $[0, \Theta]$ (so that total demand is equal to $\Theta$ ). Parameter $\theta$ represents the consumers' marginal willingness to pay for quality. Each consumer is assumed to buy at most one unit of the vertically differentiated good in order to maximise the following surplus function:

$$
U=\theta q_{i}-p_{i}
$$

where $q_{i} \in[0, Q]$ indicates the quality of the product and $p_{i}$ is the market price at which that variety is supplied by firm $i=H, L$, with $q_{H} \geq q_{L}$. Therefore, the consumer who is indifferent between $q_{H}$ and $q_{L}$ is identified 
by the level of marginal willingness to pay $\widehat{\theta}$ that solves

$$
\widehat{\theta} q_{H}-p_{H}=\widehat{\theta} q_{L}-p_{L}
$$

and therefore $\widehat{\theta}=\left(p_{H}-p_{L}\right) /\left(q_{H}-q_{L}\right)$. Thus, market demand for the highquality good is $x_{H}=\Theta-\widehat{\theta}$. We assume partial market coverage, so that there is another consumer, identified by $\widetilde{\theta}$, who is indifferent between buying $q_{L}$ or not buying at all:

$$
\widetilde{\theta} q_{L}-p_{L}=0
$$

whereby $\widetilde{\theta}=p_{L} / q_{L}$ and the demand for the inferior variety is $x_{L}=\widehat{\theta}-\widetilde{\theta}$. Accordingly, we can define consumer surplus as follows:

$$
C S=\int_{\widetilde{\theta}}^{\widehat{\theta}}\left(k q_{L}-p_{L}\right) d k+\int_{\widehat{\theta}}^{\Theta}\left(z q_{H}-p_{H}\right) d z .
$$

This is what one needs to use in order to model Bertrand behaviour, while inverse demands

$$
\begin{gathered}
p_{H}=\left(\Theta-x_{H}\right) q_{H}-q_{L} x_{L} \\
p_{L}=\left(\Theta-x_{H}-x_{L}\right) q_{L}
\end{gathered}
$$

are to be used under Cournot competition.

On the supply side, as in Ronnen (1991) and Motta (1993), inter alia, firms incur in convex fixed costs of quality improvement $C_{i}=c q_{i}^{2}, i=H, L$. Variable costs are assumed away. Hence profit functions are $\pi_{H}=p_{H} x_{H}-c q_{H}^{2}$ and $\pi_{L}=p_{L} x_{L}-c q_{L}^{2}$.

Production entails a negative environmental externality $s=b\left(x_{H}+x_{L}\right)^{2}$, with $b>0$, measuring the negative impact of production on the environment. Also, note that consumers are assumed to be myopic, in the sense that (1) does not account for the presence of pollution. ${ }^{1}$ Social welfare is determined

\footnotetext{
${ }^{1}$ It is worth noting that this is not a crucial assumption, as admitting the possibility for consumers to be environmentally concerned, with $U=\theta q_{i}-p_{i}-s$ would not modify the expressions of $\widehat{\theta}$ and $\widetilde{\theta}$ resulting from $\widehat{\theta} q_{H}-p_{H}-s=\widehat{\theta} q_{L}-p_{L}-s$ and $\widetilde{\theta} q_{L}-p_{L}-s=-s$, respectively.
} 
by the sum of profits and consumer surplus, minus the environmental externality:

$$
W=C S+\pi_{H}+\pi_{L}-s .
$$

Competition takes place in two stages. In the first, firms choose qualities and in the second they compete in quantities. Moves are simultaneous in both stages, and the solution concept is the subgame perfect equilibrium by backward induction.

\section{Results}

To begin with, we characterise optimal outputs for any given quality pair:

$$
x_{H}^{N}=\frac{\Theta\left(2 q_{H}-q_{L}\right)}{4 q_{H}-q_{L}} ; x_{L}^{N}=\frac{\Theta q_{H}}{4 q_{H}-q_{L}}
$$

where superscript $N$ stands for Nash equilibrium. The explicit derivation of the Cournot equilibrium is omitted as it is known from Motta (1993).

We now turn to the first stage where the quality game takes place. We will prove our results by manipulating the set of the first order conditions in the two alternative cases under consideration, i.e., with or without MQS. The relevant profit functions are:

$$
\begin{gathered}
\pi_{H}=\frac{q_{H}\left[\Theta^{2}\left(2 q_{H}-q_{L}\right)^{2}-c q_{H}\left(4 q_{H}-q_{L}\right)^{2}\right]}{\left(4 q_{H}-q_{L}\right)^{2}} \\
\pi_{L}=\frac{q_{L}\left[\Theta^{2} q_{H}^{2}-c q_{L}\left(4 q_{H}-q_{L}\right)^{2}\right]}{\left(4 q_{H}-q_{L}\right)^{2}}
\end{gathered}
$$

With no MQS, the first order conditions for non cooperative profit maximization are:

$$
\begin{gathered}
\frac{\partial \pi_{H}}{\partial q_{H}}=\frac{\Theta^{2}\left(16 q_{H}^{3}-12 q_{H}^{2} q_{L}+4 q_{H} q_{L}^{2}-q_{L}^{3}\right)-2 c q_{H}\left(4 q_{H}-q_{L}\right)^{3}}{\left(4 q_{H}-q_{L}\right)^{3}}=0, \\
\frac{\partial \pi_{L}}{\partial q_{L}}=\frac{\Theta^{2} q_{H}^{2}\left(4 q_{H}+q_{L}\right)-2 c\left(4 q_{H}-q_{L}\right)^{3}}{\left(4 q_{H}-q_{L}\right)^{3}}=0 .
\end{gathered}
$$


In the regulated case, the government introduces an MQS aimed at affecting directly the behaviour of firm $L$. Firm $H$ 's FOC remains unchanged, while the regulator solves:

$$
\frac{\partial W}{\partial q_{L}}=\frac{\Theta^{2}\left[4 b q_{H}\left(3 q_{H}-q_{L}\right)+q_{H}^{2}\left(4 q_{H}+3 q_{L}\right)\right]-4 c q_{L}\left(4 q_{H}-q_{L}\right)^{3}}{2\left(4 q_{H}-q_{L}\right)^{3}}=0 .
$$

For any pair of generic qualities $\left(q_{H}, q_{L}\right)$, MQS regulation is binding (and therefore brings about an increase in both qualities) if $\partial W / \partial q_{L}>\partial \pi_{L} / \partial q_{L}$. Environmental effects being absent or not taken into account, we know from Valletti (2000) that this does not apply. Here, however, the presence of a negative externality implies that

$$
\operatorname{sign}\left\{\frac{\partial W}{\partial q_{L}}-\frac{\partial \pi_{L}}{\partial q_{L}}\right\}=\operatorname{sign}\left\{4 b\left(3 q_{H}-q_{L}\right)-q_{H}\left(4 q_{H}-q_{L}\right)\right\}
$$

whereby

$$
\frac{\partial W}{\partial q_{L}}>\frac{\partial \pi_{L}}{\partial q_{L}} \text { for all } b>\frac{q_{H}\left(4 q_{H}-q_{L}\right)}{4\left(3 q_{H}-q_{L}\right)}
$$

and conversely. Therefore, if $b$ is sufficiently large, the regulator attains a welfare increase by introducing a binding MQS.

Correspondingly, social welfare

$$
W=\frac{\Theta^{2}\left[q_{H}\left(12 q_{H}^{2}-5 q_{H} q_{L}+q_{L}^{2}\right)-2 b\left(3 q_{H}-q_{L}\right)^{2}\right]-2 c\left(q_{H}^{2}+q_{L}^{2}\right)\left(4 q_{H}-q_{L}\right)^{2}}{2\left(4 q_{H}-q_{L}\right)^{2}}
$$

is positive for all

$$
b<\frac{\Theta^{2} q_{H}\left(12 q_{H}^{2}-5 q_{H} q_{L}+q_{L}^{2}\right)-2 c\left(q_{H}^{2}+q_{L}^{2}\right)\left(4 q_{H}-q_{L}\right)^{2}}{2 \Theta^{2}\left(3 q_{H}-q_{L}\right)^{2}}
$$

with

$$
\frac{\Theta^{2} q_{H}\left(12 q_{H}^{2}-5 q_{H} q_{L}+q_{L}^{2}\right)-2 c\left(q_{H}^{2}+q_{L}^{2}\right)\left(4 q_{H}-q_{L}\right)^{2}}{2 \Theta^{2}\left(3 q_{H}-q_{L}\right)^{2}}>\frac{q_{H}\left(4 q_{H}-q_{L}\right)}{4\left(3 q_{H}-q_{L}\right)}
$$


for all

$$
c<\frac{\Theta^{2} q_{H}\left(12 q_{H}^{2}-3 q_{H} q_{L}+q_{L}^{2}\right)}{4\left(q_{H}^{2}+q_{L}^{2}\right)\left(4 q_{H}-q_{L}\right)^{2}}
$$

Note also that both firms' profits are positive for all

$$
c<\min \left\{\frac{\Theta^{2}\left(2 q_{H}-q_{L}\right)^{2}}{q_{H}\left(4 q_{H}-q_{L}\right)^{2}}, \frac{\Theta^{2} q_{H}^{2}}{q_{L}\left(4 q_{H}-q_{L}\right)^{2}}\right\}
$$

so that any

$$
c<\min \left\{\frac{\Theta^{2}\left(2 q_{H}-q_{L}\right)^{2}}{q_{H}\left(4 q_{H}-q_{L}\right)^{2}}, \frac{\Theta^{2} q_{H}^{2}}{q_{L}\left(4 q_{H}-q_{L}\right)^{2}}, \frac{\Theta^{2} q_{H}\left(12 q_{H}^{2}-3 q_{H} q_{L}+q_{L}^{2}\right)}{4\left(q_{H}^{2}+q_{L}^{2}\right)\left(4 q_{H}-q_{L}\right)^{2}}\right\}
$$

ensures the positivity of profits and welfare for a generic quality pair.

The foregoing discussion can be summarised in

\section{Proposition 1 If}

$$
c<\min \left\{\frac{\Theta^{2}\left(2 q_{H}-q_{L}\right)^{2}}{q_{H}\left(4 q_{H}-q_{L}\right)^{2}}, \frac{\Theta^{2} q_{H}^{2}}{q_{L}\left(4 q_{H}-q_{L}\right)^{2}}, \frac{\Theta^{2} q_{H}\left(12 q_{H}^{2}-3 q_{H} q_{L}+q_{L}^{2}\right)}{4\left(q_{H}^{2}+q_{L}^{2}\right)\left(4 q_{H}-q_{L}\right)^{2}}\right\}
$$

then profits and welfare are positive for all $q_{H}>q_{L}$, and

$$
\frac{\Theta^{2} q_{H}\left(12 q_{H}^{2}-5 q_{H} q_{L}+q_{L}^{2}\right)-2 c\left(q_{H}^{2}+q_{L}^{2}\right)\left(4 q_{H}-q_{L}\right)^{2}}{2 \Theta^{2}\left(3 q_{H}-q_{L}\right)^{2}}>\frac{q_{H}\left(4 q_{H}-q_{L}\right)}{4\left(3 q_{H}-q_{L}\right)} .
$$

Therefore, any

$b \in\left(\frac{q_{H}\left(4 q_{H}-q_{L}\right)}{4\left(3 q_{H}-q_{L}\right)}, \frac{\Theta^{2} q_{H}\left(12 q_{H}^{2}-5 q_{H} q_{L}+q_{L}^{2}\right)-2 c\left(q_{H}^{2}+q_{L}^{2}\right)\left(4 q_{H}-q_{L}\right)^{2}}{2 \Theta^{2}\left(3 q_{H}-q_{L}\right)^{2}}\right)$

brings about the adoption of a binding $M Q S$ regulation.

The intuition behind this result is the following. In a partially covered market with no environmental externality the only problem is the distortion of hedonic qualities driven by profit incentives, and Cournot competition is 
soft enough to imply that the MQS will not bite (as we know from Valletti, 2000). If, conversely, a negative externality increasing in industry output hinders welfare, there appears a tradeoff between increasing market coverage and decreasing pollution. The balance between the two determines whether the MQS is binding, which happens to be the case whenever the marginal social cost associated to the external effect is high enough.

\subsection{An example}

Here we show a numerical example using appropriate parameter values. Setting $\Theta=1, c=1 / 2$ and $b=1 / 10$, and solving numerically the relevant system of FOCs (i.e., (9-10) in the unregulated case and (9-11) in the regulated case), we obtain:

Table 1.

\begin{tabular}{lrr}
\hline \hline & no MQS & MQS \\
\hline \hline$q_{H}$ & 0.25194 & 0.25232 \\
$q_{L}$ & 0.09022 & 0.09924 \\
$x_{H}$ & 0.45083 & 0.44547 \\
$x_{L}$ & 0.27458 & 0.27726 \\
$C S$ & 0.04017 & 0.04111 \\
$s$ & 0.05262 & 0.05223 \\
$W$ & 0.00975 & 0.00981 \\
\hline \hline
\end{tabular}

The results with no MQS replicate those in Motta (1993) and Valletti (2000). In the regulated case, (i) both qualities increase, and the same happens to consumer surplus and social welfare; while (ii) industry output, the degree of vertical differentiation and the external effect decrease as compared to the unregulated setting. In this respect, it is worth noting that total output shrinks to contain the environmental consequences of production, and 
the increase in consumer surplus is driven by the fact that a lower degree of differentiation entails lower prices, more than offsetting the negative effect caused by the output reduction.

\section{References}

[1] Motta, M. (1993). Endogenous Quality Choice: Price vs. Quantity Competition. Journal of Industrial Economics 41: 113-131.

[2] Mussa, M. and Rosen, S. (1978). Monopoly and Product Quality. Journal of Economic Theory 18: 301-317.

[3] Ronnen, U. (1991). Minimum Quality Standards, Fixed Costs, and Competition. RAND Journal of Economics 22: 490-504.

[4] Valletti, T. (2000). Minimum Quality Standards Under Cournot Competition. Journal of Regulatory Economics 18: 235-245. 


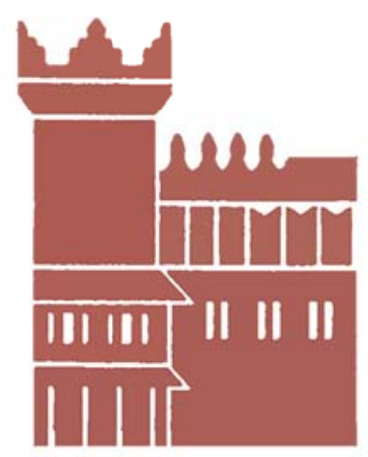

Alma Mater Studiorum - Università di Bologna DEPARTMENT OF ECONOMICS

Strada Maggiore 45

40125 Bologna - Italy

Tel. +39051 2092604

Fax +390512092664

http://www.dse.unibo.it 